\title{
Nedostaci standardnog radiograma pri obradi ozljede vratne kralježnice u visokorizičnih pacijenata - prikazi slučajeva
}

\section{Deficiency of plain film radiography in the evaluation of cervical spine injury in high-risk patient - case reports}

\author{
Tamara Petrić*, Maja Materljan, Alen Protić
}

Sažetak. Cilj: Istaknuti nedostatke standardnog radiograma pri obradi ozljede vratne kralježnice, posebice u visokorizičnih pacijenata u kojih je zbog patoanatomskih promjena ova dijagnostička pretraga otežana (ankilozantni spondilitis, stenoza spinalnog kanala i osteoporoza). Prikaz slučaja: Prikazali smo obradu ozljede vratne kralježnice u dva visokorizična pacijenta (osteoporotičnog te pacijenta $s$ ankilozantnim spondilitisom). Prijelomi vratne kralježnice češći su u te dvije skupine i mogu nastati blažim padom. Mehanizam ozljede je u oba slučaja bio pad sa svoje visine. Inicijalni neurološki pregled kod oba pacijenta bio je uredan, tek je odgođeni pregled ukazao na neurološki deficit: u prvom slučaju nekoliko sati nakon ozljede, a u drugom slučaju devet dana nakon ozljede. U oba slučaja ozljeda vratne kralježnice bila je dijagnosticirana naknadno učinjenim MSCT-om vratne kralježnice. Zaključak: S obzirom na potencijalno opasne posljedice neprepoznate i neliječene ozljede vratne kralježnice, htjeli smo naglasiti potrebu za daljnjim istraživanjem i kreiranjem adekvatnog algoritma za visokorizične pacijente. Zbog svoje visoke specifičnosti i senzitivnosti, MSCT bi trebao biti metoda izbora pri dijagnosticiranju ozlijede vratne kralježnice u toj grupi pacijenata.

Ključne riječi: MSCT vratne kralježnice; ozljeda vratne kralježnice; visokorizični pacijenti

Abstract. Aim: to emphasize the deficiencies of plain film radiographs in the evaluation of cervical spine injuries especially in high-risk patients in which this diagnostic procedure is inadequate due to pathoanatomical changes (ankylosing spondilytis, spinal canal stenosis and osteoporosis). Case report: We presented the evaluation of cervical spine injury in two high risk groups (osteoporotic patient and patient with ankylosing spondilytis). Spinal fractures are more common in those two groups and can result from a simple fall. The mechanism of injury in both cases was falling from its height. Initial neurological status was normal, only secondary approach revealed neurological deficit; in 1 . case couple of hours after injury and in 2. case nine days after injury. In both cases, MSCT revealed cervical spine fracture. Conclusion: Considering the potential severe consequences of unrecognized and untreated injuries, we wanted to emphasise the need for further research and implementation of appropriate evaluation algorithm in high-risk patients. Due to its high specificity and sensitivity, MSCT should be the method of choice in diagnosing cervical spine fracture in this group of patients.

Key words: Cervical spine MSCT; cervical spine injury; high risk patients
Objedinjeni hitni bolnički prijam, Klinika za anesteziologiju i intenzivno liječenje, Klinički bolnički centar Rijeka, Rijeka
*Dopisni autor:

Tamara Petrić, dr. med. OHBP - lokalitet Sušak, KBC Rijeka, Tome Strižića 3, 51000 Rijeka e-mail: tamarapetric08@gmail.com

http://hrcak.srce.hr/medicina 


\section{UVOD}

Teške ozljede vratne kralježnice najčešće pogađaju mlađu populaciju te su povezane $s$ mehanizmom ozljeđivanja kao što su pad s visine ili prometne nezgode na motociklu ${ }^{1,2}$. lako im je incidencija vrlo rijetka (ukupno 2,4 \% ukupnih hitnih bolničkih prijama) predstavljaju važan socijalni i ekonomski značaj jer češće pogađaju mlađe odrasle osobe i nerijetko rezultiraju trajnim neurološkim deficitom².

lako standardni radiogram ima visoku stopu dijagnostičkih pogrešaka, još uvijek je primarna slikovna metoda pri dijagnostici ozljede vratne kralježnice. Stopa lažno negativnih rezultata varira među studijama, s medijanom većinom većim od $20 \%$. Otprije je poznato da su lažno negativni nalazi češći u visokorizičnih pacijenata, jer je njihove radiograme teže očitati.

Posebnu pozornost treba obratiti na pacijente povećanog rizika, a to su stariji pacijenti i pacijenti s postojećom patologijom spinalnog kanala, poput ankilozantnog spondilitisa, stenoze spinalnog kanala i osteoporoze. U takvih pacijenata do ozljede vratne kralježnice može doći i prilikom slabijeg mehanizma ozljede kao što je pad sa svoje visine ili pad iz sjedećeg položaja ${ }^{2,3}$. Razlog je tomu manja gustoća kostiju i prisutnost degenerativnih promjena $^{3}$. Iz istih je razloga u takvih pacijenata veća incidencija radiološki negativnih nalaza. Također je unutar te rizične skupine pacijenata statistički češća ozljeda gornjeg dijela cervikalnog kanala, atlantoaksijalnog prijelaza te cervikotorakalnog prijelaza i posteriornih struktura ${ }^{3,4}$.

Unatoč većoj preciznosti MSCT-a standardni radiogram još je uvijek primarna slikovna metoda u dijagnostici ozljeda vratne kralježnice ${ }^{2,3}$. Standardno se izvode 3 projekcije: anteroposteriorna, lateralna i uz otvorena usta (odontoid). Senzitivnost pri detekciji frakture je $83-93 \%^{2}$. Postotak lažno negativnih nalaza varira između studija, medijan iznosi oko $20 \%$, a najčešći uzrok je neadekvatni radiogram, posebice u visokorizičnih pacijenata ${ }^{2,5}$.

MSCT je neophodan kako bi se isključila okultna ozljeda vratne kralježnice te omogućila procjena onih koštanih regija koje nisu adekvatno prikaza- ne standardnim radiogramom, kao i leđne moždine. Senzitivnost ove pretrage iznosi 95 - $98 \%$, a specifičnost $93-100 \%$, stoga se preporučuje za probir visokorizičnih pacijenata ${ }^{2,5}$. MRI se koristi u procjeni ozljeda leđne moždine, ekstraduralnog prostora te ligamentoznog aparata.

Cilj rada je istaknuti nedostatke standardnog radiograma prilikom procjene ozljede vratne kralježnice, posebice u rizičnih pacijenata. U tekstu koji slijedi prikazana su dva slučaja iz KBC-a u Rijeci koja to potvrđuju.

\section{PRIKAZ SLUČAJA I}

Pacijentica u dobi od 66 godina zaprima se na odjel hitne medicine nakon epizode sinkope. Prema heteroanamnestičkim podacima pala je sa svoje visine. Tijekom fizikalnog pregleda ustanovljena je hiperemija kože čela te kontuzija lijevog gornjeg kapka. Odmah po prijamu pacijentica se žalila na bol u vratu te je vrat imobiliziran Shantzovim ovratnikom. Inicijalni neurološki pregled bio je uredan. Standardni radiogrami vratne kralježnice nisu ukazali na ozljedu. Sat vremena nakon prijama pacijentica se počela žaliti na utrnutost obje ruke iznad laktova. Ponovljeni neurološki pregled otkrio je dizesteziju na C5 razini. Učinjeni MSCT vratne kralježnice otkrio je višestruki prijelom C2 kralješka te jednostavni prijelom C4 kralješka s intaktnim parenhimom leđne moždine (slika 1 i 2). Pacijentica je liječena konzervativno te se oporavila bez komplikacija.

\section{PRIKAZ SLUČAJA II}

Pacijent u dobi od 67 godina dovezen je vozilom HMP-a na Odjel hitne medicine. Prezentira se prolaznim poremećenim mentalnim statusom, tetraparezom, hipotenzijom i bradikardijom. Prema anamnestičkim i heteroanamnestičkim podacima pao je sa svoje visine nakon sinkope inducirane intoksiciranim stanjem 9 dana prije prijama. Odmah nakon pada zaprimljen je i obrađen u lokalnoj bolnici. Od simptoma navodi bol u vratu uz uredan neurološki status. Standardni radiogrami vratne kralježnice ukazali su na promjene udružene $s$ ankilozantnim spondilitisom, ali bez znakova za ozljedu vratne kralježnice. Stanje pacijenta se toga dana poboljšalo te je otpušten kući i bio je asimptomatičan sve do dana prijama 


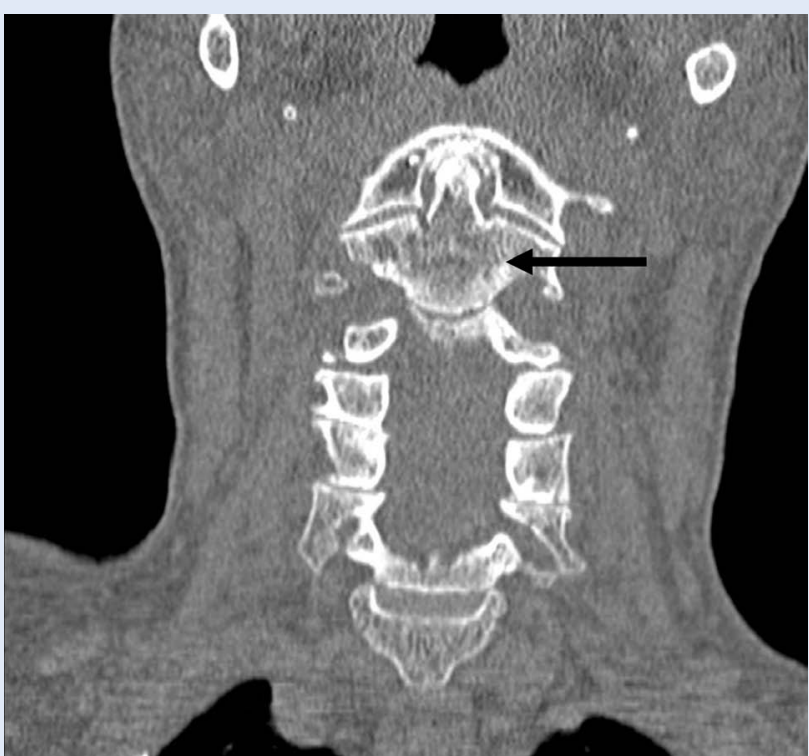

Slika 1. MSCT cervikalne kralježnice, antero-posteriorni prikaz: poprečni prijelom trupa C2 kralješka (strjelica); suphondralna skleroza prednjeg luka atlasa - degenerativne promjene.

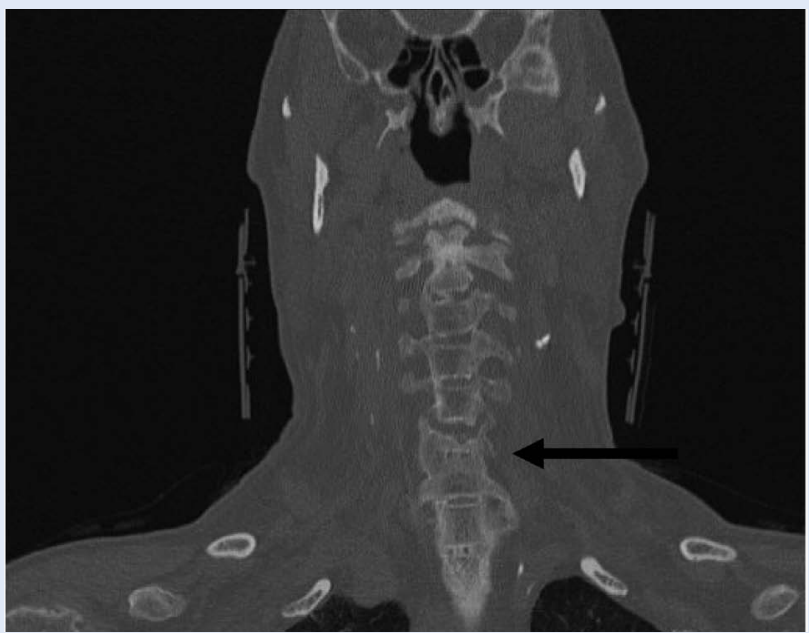

Slika 3. MSCT cervikalne kralježnice, antero-posteriorni prikaz: kompresivni prijelom trupa C6 kralješka (strjelica), paravertebralna osifikacija karakteristična za ankilozantni spondilitis

\section{Nedostatak postojećih smjernica (engl. C-Spine} Rule, NEXUS) jest u tome što ne uključuju pacijente s podliježućom patologijom vratne kralježnice kao jednim od kriterija za procjenu rizika. Ovim smo radom htjeli naglasiti potrebu za daljnjim istraživanjem upravo te populacije sa svrhom implementacije prikladnog algoritma dijagnosticiranja.

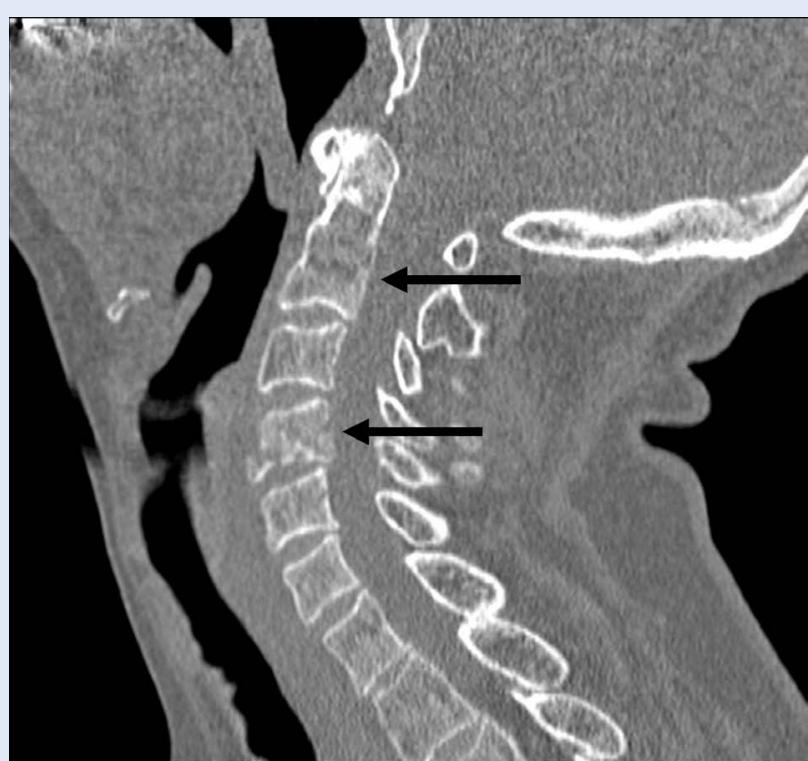

Slika 2. MSCT cervikalne kralježnice, sagitalni prikaz: poprečni prijelom trupa C2 kralješka (gornja strjelica), fraktura trupa C4 kralješka s manjom dislokacijom prednjeg frakturnog ulomka (donja strjelica).

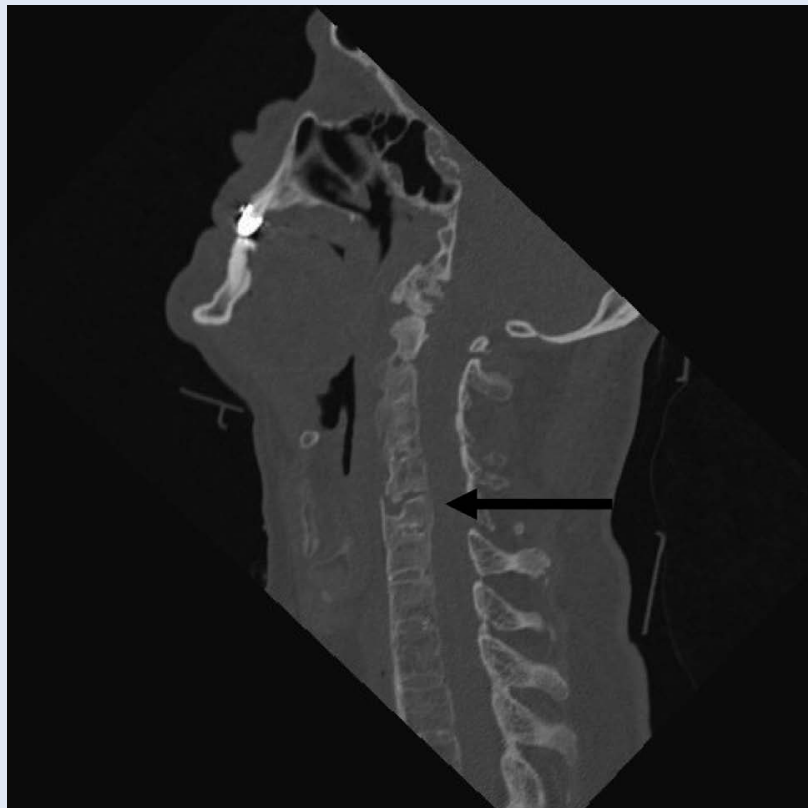

Slika 4. MSCT cervikalne kralježnice, sagitalni prikaz: kompresivni prijelom trupa C6 kralješka (strjelica), kalcificiran prednji longitudinalni ligament na razini trupa C5 kralješka

u našu ustanovu. Učinjeni MSCT vratne kralježnice otkrio je prijelom C5 kralješka $s$ dislokacijom ulomaka od 2 mm (slika 3 i 4). Pacijent je liječen konzervativno i oporavio se bez komplikacija. 


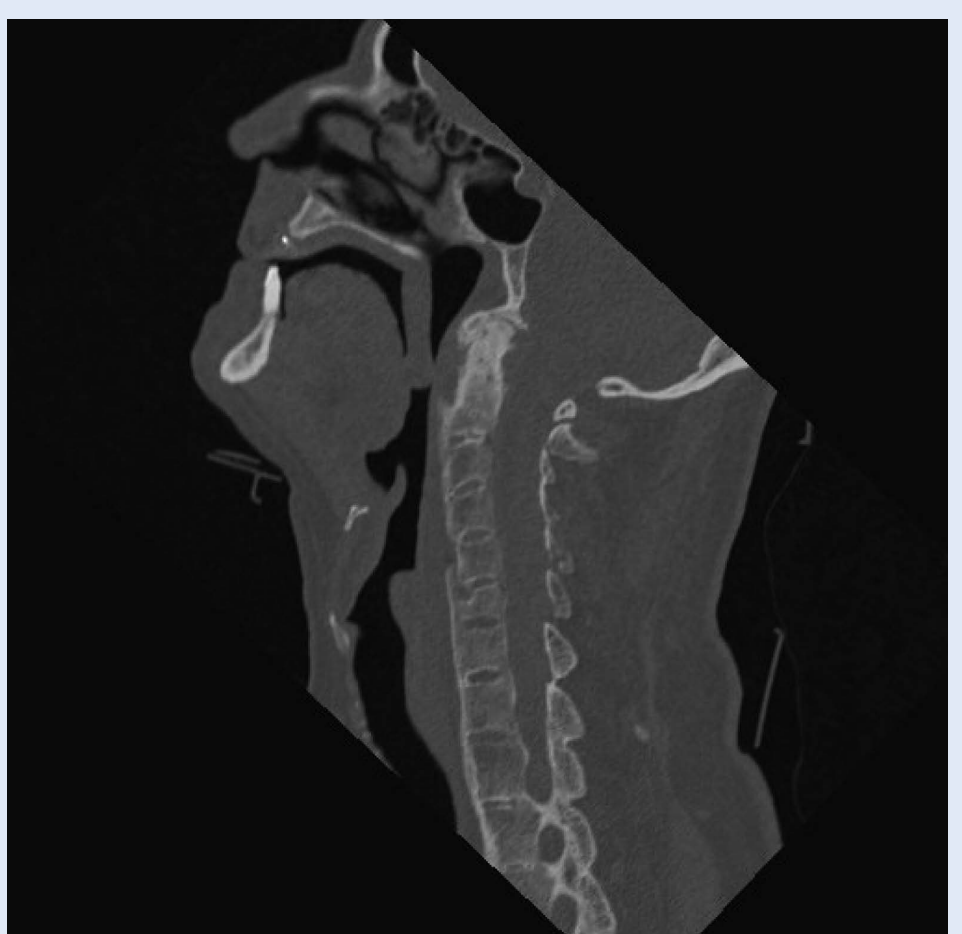

Slika 5. MSCT cervikalne kralježnice, sagitalni prikaz: fuzija trupova kralježaka sindezmofitima - „kralježnica poput bambusova štapa“, deformirani odontoidni nastavak C2 kralješka, kalcificirani prednji i stražnji longitudinalni ligament - karakteristike ankilozantnog spondilitisa

\section{RASPRAVA}

Ozljede vratne kralježnice u hitnoj medicini dijele se na one visokog i niskog rizika, a pritom se liječnici oslanjaju na NEXUS kriterije i tzv. Canadian C Spine Rule. Općepoznato je da su pacijenti s višestrukim ozljedama skloni neprepoznatoj ozljedi vratne kralježnice ${ }^{1}$. NEXUS kriteriji uključuju palpatornu osjetljivost u području vratne kralježnice, intoksikaciju pacijenta, razinu svijesti, neurološki deficit te udruženu ozljedu koja pacijentu odvlači pozornost (tablica 1). Canadian C Spine Rule uključuje dob iznad 65 godina, ozbiljan mehanizam ozljede (npr. pad s 2 m visine i viši, veća prometna nezgoda) te opseg kretnji vratne kralježnice (tablica 2). Pacijenti srednjeg i visokog rizika zahtijevaju radiološku dijagnostiku, a nerijetko i potvrdu MSCT-om, dok se pacijenti bez rizika mogu sigurno otpustiti kući. Nedostatak obaju smjernica jest u tome što ne uključuju pacijente s podliježućom patologijom vratne kralježnice kao posebnom vrstom rizične skupine. Ovim smo radom upravo na njih htjeli skrenuti pozornost.

Prikazali smo dva primjera obrade visokorizičnih pacijenata; osteoporotičnog pacijenta (prvi slučaj) te pacijenta s ankilozantnim spondilitisom (drugi slučaj). U oba slučaja potvrđena je ranija poznata teza da su pogreške u čitanju standardnog radiograma češće upravo u rizičnih pacijenata. Najčešće pogreške odnose se na osteopeniju, preklapajuće strukture, lošu ekspoziciju i kvalitetu filma te motiviranost dijagnostičara ${ }^{6}$. Što se tiče lokalizacije prijeloma dokazano je da se najčešće previđaju prijelomi u području gornjeg cervikalnog segmenta, cervikotorakalnog prijelaza te posteriornih segmenata ${ }^{4}$. U pacijenata s ankilozantnim spondilitisom imamo fenomen premošćivanja kralježaka, njihovu fuziju i posljedičnu lošu kvalitetu radiograma ${ }^{7}$.

Također je potvrđen podatak da i manji mehanizam ozljede može uzrokovati ozljedu. Naime, rigiditet fuzioniranih kralježaka, primjerice u pacijenata $s$ ankilozantnim spondilitisom, pridonosi lakšem prijelomu ${ }^{7}$. Slično je i s degenerativnim promjenama u starijih osoba ${ }^{3}$.

Tablica 1. NEXUS kriteriji za procjenu ozljede cervikalne kralježnice (u slučaju jednog negativnog kriterija nužna je radiološka obrada)

\begin{tabular}{|l|l|}
\hline Palpatorno bezbolna vratna kralježnica & DA/NE \\
\hline Nema znakova intoksikacije pacijenta & DA/NE \\
\hline Pacijent je pri svijesti, orijentiran u sva 3 pravca & DA/NE \\
\hline Nema fokalnog neurološkog deficita & DA/NE \\
\hline Nema udruženih ozljeda (koje kliničaru otklanjaju pozornost) & DA/NE \\
\hline
\end{tabular}

Tablica 2. Canadian C-Spine Rule (ako je pozitivan jedan od tri kriterija, nužna je daljnja radiološka dijagnostika)

\begin{tabular}{|l|l|}
\hline Dob iznad 65 godina & DA/NE \\
\hline Parestezija ekstremiteta & DA/NE \\
\hline $\begin{array}{l}\text { Opasni mehanizam ozljede (pad s visine od } 3 \mathrm{~m} / 5 \text { stepenica, prometna nezgoda pri velikim } \\
\text { brzinama, sudar biciklista i sl.) }\end{array}$ & DA/NE \\
\hline
\end{tabular}


U oba slučaja MSCT vratne kralježnice otkrio je ozljedu vratne kralježnice - frakturu nakon urednih standardnih radiograma. U nedavnim je studijama ukazano da je MSCT vratne kralježnice dominantna strategija prevencije trajnog neurološkog deficita te da je čak i isplativija metoda dijagnostike ${ }^{5}$. Također se preporučuje kao primarni dijagnostički odabir u politraumatiziranih pacijenata te u pacijenata u kojih je nemoguća adekvatna klinička evaluacija i otežana izvedba radiograma ${ }^{4}$.

MRI prednjači u dijagnostici ozljeda mekih tkiva (ekstraduralnog prostora, leđne moždine i ligamentoznog aparata). Koristi se prvenstveno za detekciju radiološki nedetektibilnih ozljeda leđne moždine tzv. SCIWORA-e (engl. Spinal Cord Injury Without Radiographic Abnormality) u pacijenata $\mathrm{s}$ prisutnim neurološkim deficitom ${ }^{2,4}$. Navedeni termin vrlo je rijedak u odraslih (s incidencijom od oko 3,5 - 3,8 \% svih ozljeda leđne moždine) te je karakterističan za pedijatrijsku populaciju ${ }^{2,8}$.

U prvom slučaju neurološki simptomi pojavili su se nekoliko sati nakon ozljede. U drugom slučaju neurološki deficit razvio se mnogo kasnije (osam dana). Poznato je da prijelomi mogu biti nedetektirani do pojave neuroloških simptoma, što ponekad može trajati i tjednima. Period pojave neurološkog deficita varira od slučaja do slučaja. Primjerice, u jednoj studiji ukazano je da se odgođeni neurološki odgovor javlja u preko $20 \%$ slučajeva primarno neprepoznate dijagnoze ${ }^{7}$. To, kao i oba ovdje prikazana slučaja, upućuje na važnost strukturalnog neurološkog pregleda i potrebu njegova ponavljanja.

Ako nije na vrijeme prepoznata, ozljeda cervikalne kralježnice nosi sa sobom sve rizike kirurškog liječenja i posljedičnog lošijeg neurološkog oporavka u odnosu na konzervativno liječenje ${ }^{9}$. U oba naša pacijenta na vrijeme je otkrivena fraktura, liječeni su konzervativno i oporavili se bez komplikacija.

\section{ZAKLJUČAK}

Previđene ozljede vratne kralježnice daleko su češće u cervikalnom nego u torakalnom ili lumbosakralnom dijelu, u pacijenata s poremećajem svijesti, politraumatiziranih, inotoksiciranih pacijenata te pacijenata s podliježućom patologijom vratne kralježnice ${ }^{9}$. Upravo takvih činjenica moramo biti svjesni prilikom evaluacije pacijenata $s$ potencijalnom ozljedom vratne kralježnice, kao i faktora tehničke izvodljivosti i motiviranosti radiologa - s namjerom unaprjeđenja dijagnostike traume vratne kralježnice. Obradu pacijenta mora pratiti dobro strukturiran neurološki pregled uz njegovo eventualno ponavljanje tijekom obrade ili po prijamu na bolničko liječenje.

Radom smo htjeli naglasiti kako bi, s obzirom na visoku specifičnost i senzitivnost, MSCT bio metoda izbora u dijagnostici prijeloma vratne kralježnice upravo u takvih pacijenata. Nadalje, vidljiva je potreba za daljnjim istraživanjem u istom području sa svrhom implementacije. Na primjeru ovih dvaju pacijenata potvrdili smo već poznatu raniju tezu da se preciznijom dijagnostikom MSCT-om, kojom se generira adekvatnije neurokirurško liječenje, prevenira neurološki deficit, a time i produljeno kirurško i najčešće manje efektivno liječenje.

\section{ZAHVALE}

Zahvaljujemo kolegici Tijani Grubešić, dr. med. s Kliničkog zavoda za radiologiju za pomoć oko uređivanja slika.

Izjava o sukobu interesa: Autori izjavljuju da ne postoji sukob interesa.

\section{LITERATURA}

1. Clubb R. Delayed Diagnosis of a Patient with Cervical Spine Injury resulting in Complete Cervical Spine Dislocation without Serious or Lingering Neurological Signs: A Case Report. The Internet Journal of Emergency Medicine 2006;4:1.

1. Koivikko M. Cervical Spine Injuries in Adults: Diagnostic Imaging and Treatment Options. Univerity of Helsinki, Finland. 2005. PhD thesis.

2. Walid SM, Zaytseva NV. Upper Cervical Spine Injuries in Elderly Patients. Aust Fam Physician 2009;38:43-5.

3. Ansari S, Rauniya RK, Ahmad K, Gupta KM. Multidetector Computed Tomographic Evaluation of Cervical Spine Trauma. Indian Journal of Basic \& Applied Medical Research 2013;2:1052-60.

4. Blackmore C, Ramsey S, Mann F, Deyo R. Cervical Spine Screening with CT in Trauma Patients: A Cost-effectiveness Analysis. Radiology 1999;212:117-25.

5. Anbari MM, Clark West O. Cervical Spine Trauma Radiography: Sources of False - Negative Diagnoses. Emergency radiology 1997;4;8:218-24.

6. Bernstein PM, Baxter BA. Cervical Spine Trauma: Pearls and Pitfalls. In: Pitfalls in Clinical Imaging. The American Roentgen Ray Society, 2012:21-5.

7. Kothari P, Freeman B, Grevitt M, Kerslake R. Injury to the Spinal Cord Without Radiological Abnormality (SCIWORA) in Adults. J Bone Joint Surg Br 2000;82:1034-7.

8. Sengupta DK. Neglected spinal injuries. Clin Orthop Relat Res 2005;431:93-103. 